\title{
Herpes simplex induced erythema multiforme - A case report
}

\author{
Raghavendra H. Gobbur ${ }^{1, *}$, Sanjeevini Umrani ${ }^{2}$ \\ ${ }^{1}$ Professor, ${ }^{2}$ Resident, Dept. of Paediatrics, BLDEU'S SBM Patil Medical College, Vijayapur, Karnataka
}

*Corresponding Author:

Email: rhgobbur@gmail.com

\begin{abstract}
Erythema Multiforme is an acute inflammatory muco-cutaneous hypersensitive reaction with varied aetiology and various degrees of blistering and ulceration. Viral aetiology is most common. We report a case of herpes induced Erythema Multiforme who was managed with acyclovir. The 11 year old boy presented with pain and ulceration over his lips, target shaped lesions on palms and fever. The episode was not drug related. The presentation suggested Herpes associated Erythema Multiforme which was confirmed by Serology positive for Herpes simplex virus. The patient was treated with acyclovir for 7 days and his illness subsided. The early suspicion and initiation of treatment is necessary in management of this life threatening mucocutaneous disorder.
\end{abstract}

Keywords: Herpes simplex, Erythema Multiforme, target lesions, acyclovir.

\section{Case History}

A 11-year-old boy presented with history of swelling of upper and lower lip with pain and ulceration since 1 week. He had reddish tongue and redness of right eyes. He had fever 3 days back for which he was treated with NSAIDS.

He also had classical target lesions over his palms (see the arrow in the photograph of hand). Oral lesions were followed by dermal lesions. Oral lesions were accompanied with pain which was severe and which aggravated on mastication. Past medical history was not significant. The patient had no prolonged drug intake and hospitalization, and his family and drug history were also not significant. His vital signs were stable.

Serology tests were done which was positive for Herpes simplex virus (HSV) IgM. Diagnosis of Herpes associated erythema multiforme (HAEM) was done. The boy was treated with a 7-day course of acyclovir, a topical steroids and acetaminophen. The lesions healed within a week.

\section{Aetiology of EM}

The erythema multiforme (EM) is a clinical entity which mirrors the wide morphological range of the lesions. ${ }^{1}$ Erythema multiforme lesions have been caused by various factors, especially infections (90\% cases), particularly herpes simplex infection (HSV) yet different herpes viruses (varicella-zoster infection, cytomegalovirus, Epstein-Barrvirus), adenoviruses, enteroviruses (Coxsackie infection B5, echoviruses), hepatitis infections (A, B and C), flu, paravaccinia, parvovirus B19, poliomyelitis, vaccinia and variola have all been implicated. ${ }^{2}$

Another prominent infectious agent which is associated with EM is Mycoplasma pneumoniae which is of prime importance in development of EM in children. ${ }^{3}$ In less than $10 \%$ of cases, drugs like nonsteroidal anti-inflammatory drugs, sulphonamides, antiepileptic, and antibiotics can also be associated with EM. $^{3}$

\section{Differential Diagnoses}

Resemblers of EM include Urticaria, StevensJohnson syndrome, fixed drug eruption, bullous Pemphigoid, Paraneoplastic Pemphigus, Sweet's syndrome, Rowell's syndrome, polymorphus light eruption, and cutaneous small-vessel vasculitis. ${ }^{3}$

Instances of Herpes related erythema multiforme (HAEM) can regularly be mistaken for StevenJohnsons disorder (SJS) and Toxic epidermal Necrolysis (TEN). HAEM can be recognized from SJS by the nearness of ordinary target lesions on the skin with or without mucosal contribution. At the point when mucosal association is display in HAEM, it is constrained to a solitary mucosal site as opposed to at least two separate mucosal locales as observed in SJS. HAEM settle without sequelae inside two weeks, though SJS regularly keeps going longer than two weeks, leaving scars and could likewise have instinctive inclusion. ${ }^{4}$ TEN, then again, is an uncommon clinicopathological element, with a high mortality, described by broad separation of full thickness epidermis. ${ }^{5}$ While the reason of HAEM is viral disease, SJS and TEN are caused systemic drugs in $80 \%$ of the cases. $^{6}$

\section{Discussion}

Erythema multiforme (EM) is a dangerous mucocutaneous issue where early diagnosis and administration is of most extreme vital. It can actuate by different etiological factors; viral aetiology is the most well-known. EM is seen typically in young adults, though $20 \%$ of cases happen in children. The illness is more typical in males than females and is accelerated by going before herpes disease in up to $70 \%$ of cases. ${ }^{7,8}$

EM starts with an intense beginning and, generally, gentle or no prodromal manifestations. Fever, 
lymphadenopathy, malaise, headache, cough, sore throat and polyarthralgia may be noticed as much as 1 week before the onset of surface erythema or blisters..$^{9,10}$ Lesions may appear as irregular red macules, papules and vesicles that collapse and gradually enlarge to form plaques on the skin. ${ }^{10}$ Crusting and blistering occur in the centre of the skin lesions, appearing as concentric rings resembling a "bull's eye" (target lesion). ${ }^{3}$ On the other hand, oral lesions are erythematous macules on the lips and buccal mucosa which are followed by epithelial necrosis, bullae and ulcerations with an irregular outline and inflammatory halo. ${ }^{10}$

The diagnosis of HAEM is mostly clinical and it becomes easier when the patient develops target lesions with a preceding or coexisting HSV infection. ${ }^{11}$ The finding of skin or oral lesions in a patient with suspected HAEM supports the clinical diagnosis. ${ }^{3}$ In our case, diffuse ulcerations in the oral mucosa involving the labial mucosa and haemorrhagic crusts on the lips were also seen, as well as the classic skin lesions.

There is no precise diagnostic investigation for EM. ${ }^{3}$ The vital clues for HAEM continue to be the clinical history and clinical findings. Significant components of the history with: (1) an acute, selflimiting course, (2) signs and symptoms of associated infections, such as HSV, and (3) a history of the use of new medication. ${ }^{3}$

Clinical clues to diagnosis comprise the presence of target lesions, raised atypical papules or mucosal involvement, or a combination of these. ${ }^{3}$

Treatment of EM depends on the severity of the lesions. Milder forms take 2-6 weeks to heal and it includes local wound care, topical analgesics or local anaesthetics for pain control and a liquid diet. ${ }^{4}$ For more severe cases, intensive management with intravenous fluid therapy may be necessary. ${ }^{4}$ Oral antihistamines and topical steroids also provide symptom relief. Systemic corticosteroid have been used successfully in some patients, but has less evidence for its use. ${ }^{4}$

Recurrence is seen in about 20-25\% of EM cases. ${ }^{7,9}$ Some patients have 2-24 episodes a year. HAEM is treated with acyclovir, along with supportive medications. If EM keeps recurring, a continuous low dose of oral acyclovir is necessary. ${ }^{7}$ Oral acyclovir is effective in preventing recurrent HAEM. ${ }^{7}$ If acyclovir treatment fails, valacyclovir can also be prescribed, which being a pro drug has better absorption and pharmacokinetics. $^{7}$

Funding: No funding sources.

Conflict of interest: None declared.

\section{References}

1. Aurelian L, Ono F, Burnett J. Herpes simplex virus (HSV)-associated erythema multiforme (HAEM): a viral disease with an autoimmune component. Dermatol Online J 2003;9(1):1.

2. Tatnall FM, Schofield JK, Leigh IM. A double-blind, placebo-controlled trial of continuous acyclovir therapy in recurrent erythema multiforme. Br J Dermatol 1995;132(2):267-70.

3. Sokumbi O, Wetter DA. Clinical features, diagnosis, and treatment of erythema multiforme: A review for the practicing dermatologist. Int J Dermatol 2012;51:889902.

4. Weston WL, Morelli JG. Herpes simplex virus associated erythema multiforme in pre pubertal children. Arch Pediatr Adolesc Med 1997;151(10):1014-16.

5. Farthing P, Bagan JV, Scully C. Mucosal diseases Series. Number IV. Erythema multiforme. Oral Dis 2005;11(5):261-67.

6. Carozzo M, Togliatto M, Gandolfo S, [Erythema multiforme. A heterogenous pathologic phenotype]. Minerva Stomatol 1999;48(5):217-26.

7. Sen P, Chua SH. A case of recurrent erythema multiforme and its therapeutic complications. Ann Acad Med Singapore 2004;33:793-6.

8. Simbli MA. Erythema multiforme: Challenging diagnosis for internist. J Clin Case Rep 2013;3:285-8

9. Osterne RL, de Matos Brito RG, Pacheco IA, Alves AP, Sousa FB. Management of erythema multiforme associated with recurrent herpes infection: A case report. J Can Dent Assoc 2009;75:597-601.

10. Kishore M, Panat SR, Aggarwal A, Upadhyay N, Agarwal N. Herpes associated erythema multiforme-a diagnostic dilemma. Int J Sci Study 2013;01(02):82-6.

11. Rahman MR, Shahriar R, Afroze SR, Khan MM, Uddin KN, Islam MN. Herpes Associated Erythema Multiforme: A Case Report. BIRDEM Med J [Internet]. 2017;7(1):72. Available from

http://www.banglajol.info/index.php/BIRDEM/article/vie w/31277

How to cite the article: Gobbur R., Umrani S. Herpes simplex induced erythema multiforme - A case report. IP Int J Med Paediatr Oncol 2018;4(3):131-132. 